\title{
Retorno do sarampo: entre a fake news e a Saúde Pública
}

\author{
Measles return: between fake News and Public Health \\ Regreso del sarampión: entre las noticias falsas y la Salud Pública
}

\section{Resumo}

O presente artigo objetivou discutir a relação da vacina para prevenção das doenças: sarampo, caxumba e rubéola com uma deficiência neural do desenvolvimento - isto é, autismo - uma contextualização falsa que fortaleceu o movimento antivacina, o qual permanece até os dias atuais, principalmente, por meio das fake news. Consequentemente, um forte contribuinte para a reintrodução do sarampo no Brasil e no mundo. Por se tratar de uma revisão narrativa, a metodologia empregada foi composta por 33 artigos selecionados em bases de dados e materiais de literatura acadêmicas com o intuito de atualizar o entendimento sobre o tema e seu cenário. Indiscutivelmente, os muitos estudos analisados garantem a fraude no movimento antivacina, negando a relação da vacinação e do autismo. Além dos resultados assegurarem surtos de sarampo tanto no Brasil quanto em diversas partes do mundo. Desse modo, o artigo tem por finalidade ressaltar a importância da imunização no aspecto pessoal e coletivo e a conscientização popular para eliminar a reincidência de doenças já erradicadas, preservando uma saúde pública eficiente.

Palavras-chave: Saúde pública; Vacinação; Sarampo; Movimento contra vacinação; Autismo.

\begin{abstract}
This article aimed to discuss the relationship between vaccine for disease prevention: measles, mumps and rubella with a neural deficiency in development - that is, autism - a false contextualization that strengthened the anti-vaccine movement, which remains today, mainly, through fake news. Consequently, a strong contributor to the reintroduction of measles in Brazil and worldwide. As this is a narrative review, the methodology used was composed of 33 articles selected from databases and academic literature materials in order to update the understanding of the topic and its scenario. Arguably, the many studies analyzed guarantee fraud in the anti-vaccine movement, denying the link between vaccination and autism. In addition to the results ensure measles outbreaks both in Brazil and in different parts of the world. Thus, the article aims to emphasize the importance of immunization in the personal and collective aspect and popular awareness to eliminate the recurrence of diseases already eradicated, preserving an efficient public health.
\end{abstract}

Keywords: Public health; Vaccination; Measles; Anti-vaccination movement; Autism.

\section{Resumen}

Este artículo tuvo como objetivo discutir la relación entre la vacuna para la prevención de enfermedades: sarampión, paperas y rubéola con una deficiencia neuronal en desarrollo - es decir, autismo - una falsa contextualización que fortaleció el movimiento antivacunas, que permanece hoy, principalmente, a través de fake news. En consecuencia, un fuerte contribuyente a la reintroducción del sarampión en Brasil y en todo el mundo. Al tratarse de una revisión narrativa, la metodología utilizada estuvo compuesta por 33 artículos seleccionados de bases de datos y materiales de literatura académica con el fin de actualizar la comprensión del tema y su escenario. Podría decirse que los numerosos estudios analizados garantizan el fraude en el movimiento antivacunas, negando el vínculo entre la vacunación y el autismo. Además los resultados aseguran brotes de sarampión tanto en Brasil como en diferentes partes del mundo. Así, el artículo pretende enfatizar la importancia de la inmunización en el aspecto personal y colectivo y la conciencia popular para eliminar la recurrencia de enfermedades ya erradicadas, preservando una salud pública eficiente. Palabras clave: Salud pública; Vacunación; Sarampión; Movimiento anti-vacunación; Autismo. 


\section{Introdução}

O sarampo consiste em uma doença viral altamente comum e contagiosa de agente etiológico um RNA vírus pertencente ao gênero Morbillivirus e à família Paramyxoviridae (Petraglia et al., 2020) com transmissão respiratória, ou seja, de pessoa para pessoa por meio de secreções nasofaríngeas expelidas na fala, tosse e espirro (Xavier, et al., 2019).

Em várias partes do mundo, o sarampo é uma das principais causas de morbimortalidade entre crianças menores de cinco anos de idade (Brasil, 2019a), por isso denominada como uma das infecções clássicas da infância, sem predileção por raça, gênero ou idade, mesmo com a existência de imunização/vacinação eficiente (Petraglia, et al., 2020).

A evolução científica, com a criação e introdução de vacinas, contribuiu para a prevenção e cura de doenças (Scliar, 2007). Além disso, vale destacar sua segurança e eficácia devido às várias etapas e de muitas aprovações para o uso populacional.

Entretanto, mesmo com todos os cuidados para a criação de uma vacina, o cientista britânico - Andrew Wakefield, é um nome a ser lembrado, pois, em 1998, publicou na revista científica The Lancet um estudo que relatava casos de 12 crianças que ao receberem a vacina tríplice contra sarampo, caxumba e rubéola (MMR - Measles, Mumps and Rubella - em países de língua inglesa) (Schäfer, et al., 2019) desenvolveram graves inflamações cerebrais que desencadearam o autismo.

Em decorrência disso, o estudo agravou crenças pré-existentes que, consequentemente, potencializou o movimento antivacina (corrente popular que acredita no perigo das vacinas, pois creem que, de forma natural, o organismo pode se proteger) (Vasconcellos-Silva, et al., 2014). Atualmente, esse movimento está presente em todos os continentes e, cada vez mais, tem ganhado novos seguidores, principalmente devido à globalização, internet e mídias sociais (Rao \& Andrade, 2011). No Brasil, valores filosóficos e religiosos aprofundam ainda mais o movimento.

No entanto, após alguns anos a pesquisa realizada por Wakefield foi refutada, considerada fraudulenta e relacionadas a conflitos de interesses, pois se comprovou que o cientista possuía uma associação com advogados que estimulavam as famílias às indenizações, além da descoberta de uma patente de vacina antisarampo supostamente mais segura registrada em seu nome. É indubitável: a potencialização do movimento antivacina derivou de uma conduta irresponsável e antiética (Vasconcellos-Silva, et. al., 2014).

Portanto, não se pode perpetuar a fraude do movimento antivacina. Caso contrário, a saúde pública continuará sofrendo um retrocesso e os empresários como Andrew Wakefield continuarão visando o lucro ao invés da vida social. Infelizmente, a influência de uma fraudulenta pesquisa (a qual potencializou o movimento antivacina), juntamente com a presença de fake news tem desencadeado a reintrodução do sarampo no Brasil e no mundo. Com isso, esse artigo, pretende destacar a reinserção de doenças já erradicadas e, consequentemente, um atraso à saúde pública.

\section{Metodologia}

A metodologia adotada trata-se de uma revisão narrativa, pois não segue critérios explícitos e sistemáticos ao buscar e analisar criticamente a literatura, por meio da seleção de estudos e da interpretação tanto objetiva quanto subjetiva a fim de atualizar o conhecimento sobre certo tema e circuntâncias (Rother, 2007). Desse modo, o artigo é composto por diversos artigos pesquisados em bases de dados, como: Scielo, Biblioteca Virtual de Saúde (BVS) e Google Acadêmico, além de informações obtidas por meio de materiais da literatura acadêmica, nos quais foram selecionados 33 referências, por descritores como: saúde pública, vacinação, measles, sarampo, movimento contra vacinação, anti-vaccination movement, reincidência, Andrew Wakefiel, autismo, dentre outros.

O artigo cuja construção é subsidiada na discussão em torno da contextualização do movimento antivacina atual com a reintrodução do sarampo no Brasil, país que até o ano de 2018 mantinha os casos dessa doença viral em situações praticamente nulas, prevê inicialmente a destacar o histórico do movimento antivacinação e a necessidade de conscientização 
popular no século XXI, visto a segurança e eficácia da vacinação; posteriormente, uma análise epidemiológica dos casos da doença de modo indireto, por meio de informações disponibilizadas por diversos bancos de dados tanto brasileiros quanto mundiais. Vale evidenciar que por se tratarem de dados de livre acesso no meio digital este trabalho foi dispensado de apresentação ao Comitê de Ética e Pesquisa, de acordo com a Resolução 466/2012 do Conselho Nacional de Saúde, do Ministério da Saúde do Brasil.

\section{Resultados e Discussão}

\subsection{Discussões sobre o sarampo}

O sarampo é uma doença viral altamente transmissível, podendo ocorrer de quatro a seis dias antes do surgimento de exantema (erupção cutânea) ou quatro dias após. No caso de mães acometidas pela doença, há possibilidade de transmitirem aos recém-nascidos, todavia nos primeiros seis meses, devido à transferência placentária de anticorpos maternos a transmissibilidade ao feto torna-se relativamente rara de acontecer (Xavier, et al., 2019).

O quadro clínico da enfermidade é caracterizado por febre aguda, geralmente superior à $38,5^{\circ} \mathrm{C}$, exantema cutâneo maculopapular morbiliforme de coloração vermelha de direção cefalocaudal - não coça e não dói - o qual é antecedido por manchas de Koplik, ou seja, pequenos pontos brancos na mucosa oral, mais especificamente na altura do terceiro molar, além de coriza, conjuntivite não purulenta e, inicialmente, presença de uma tosse seca. Importante observar que após o surgimento do exantema, se a febre persistir por um período superior a 3 dias é um sinal alarmante, uma vez que pode indicar o aparecimento de complicações, como: infecções respiratórias, otites, doenças diarreicas e neurológicas, o que potencializa a necessidade de internação hospitalar, empregando maior atenção às crianças desnutridas e com os mecanismos normais de defesa comprometidos (Brasil, 2019a; Petraglia, et al., 2020). Portanto, trata -se de uma doença demasiadamente contagiosa.

A principal profilaxia para o controle da doença é a vacinação. O tratamento é limitado ao suporte clínico e sintomático, uma vez que não há conduta específica contra o vírus. Outrossim, para erradicar o surto da doença é necessário coletar amostras clínicas do paciente para identificação viral por genotipagem e notificar casos suspeitos dentro de 24 horas ao Departamento de Saúde local, principalmente em indivíduos não vacinados (Xavier, et al., 2019).

\subsection{Desenvolvimento vacinal}

A vacinação não é recente. A evolução da ciência permitiu com a revolução pasteuriana no final do século XIX sua introdução em muitos casos garante prevenção e cura de doenças (Scliar, 2007). Vale destacar que são necessárias várias etapas, avaliações e aprovações para comprovação de sua eficiência e segurança e somente assim, permissão para o uso populacional.

A primeira etapa da imunização consiste em pesquisas e desenvolvimento, visando a identificação de antígenos naturais ou sintéticos que ajudem na prevenção ou tratamento da doença estudada. Ainda, há avaliações pré-clínicas sobre a segurança e imunogenicidade (capacidade de desencadear resposta inume). Com isso, são usados sistemas de cultura de tecidos ou células e, assim, testes em animais, como: macacos e ratos. Posteriormente, para testes clínicos é fundamental um protocolo de pesquisa clínica que necessita da aprovação do Comitê de Ética em Pesquisa ("CEP”) ou pelo Comitê Nacional de Ética em Pesquisa (“CONEP”). Além do mais, é preciso a submissão de um Dossiê de Desenvolvimento Clínico ("DDCM") perante a ANVISA. Só assim, é possível o início das avaliações clínicas: primeira fase - extensão da resposta imunológica - após resultados favoráveis, a fase dois que consiste no aumento do número de voluntários com a investigação da imugenicidade da vacina, os parâmetros de dosagem, métodos e cronogramas de imunização, já a terceira fase envolve um número ainda maior de pessoas para verificar efeitos colaterais antes não identificados e a validação da segurança e eficiência do produto para 
prevenção. Por fim, é solicitado um pedido de registro para comercialização (Rothbarth, 2018). No Brasil há, ainda, desde 1998, um sistema passivo de vigilância de eventos adversos pós-vacinação (SPVEAPV) (Monteiro, et al. 2011).

A vacinação é uma proteção individual de prevenção de doenças que possuem perigo de contaminação efetiva, isso porque não há o total impedimento do contágio da doença, entretanto certamente impede seu agravamento e um possível óbito. Além disso, é uma preservação coletiva, pois garante a diminuição ou extinção da carga viral, dificultando a contaminação da população (Rothbarth, 2018).

\subsection{Movimento antivacina: início da correlação da vacina tríplice viral e do autismo}

É indiscutível que Andrew Wakefiel - cientista britânico - merece destaque devido a sua publicação na revista científica The Lancet, em 1998, que descreve o caso de 12 crianças que ao receberem a vacina tríplice viral (contra sarampo, caxumba e rubéola) apresentaram o quadro de autismo (Schäfer, et al., 2019).

A pesquisa fomentou o movimento antivacina, por meio da intensificação de ideias já existentes na sociedade, porém não tão disseminados (Vasconcellos-Silva, et al., 2014). Rapidamente, o movimento espalhou-se e ganhou seguidores de todas as partes do mundo e, atualmente, a globalização atrelada ao meio digital tem contribuído para um número cada vez maior de defensores do perigo vacinal (Rao \& Andrade, 2011).

Entretanto, o estudo divulgado pelo nobre cientista, não passou de uma fraude. Posteriormente descoberta, esta foi refutada juntamente com o questionamento da relação da tríplice viral desencadeadora do autismo. Isso porque ambos os eventos ocorrem na primeira infância, ou seja, uma ligação temporal quase selecionada (Schäfer, et al., 2019).

É necessário explicitar que o autismo é uma deficiência neural do desenvolvimento, isso significa que não é uma doença imunomediada, que pode causar desafios sociais, comportamentais ou comunicacionais intensos, sendo que dados atuais pressupõe que a variação genética nos circuitos neurais (afetando o desenvolvimento sináptico) é o grande responsável pelo autismo. Ao contrário da especulação de que a uma resposta imune da vacina seria a causadora desse problema de desenvolvimento (Destefano \& Shimabukuro, 2019; Gerber \& Offit, 2009).

No entanto, com a publicação de Wakefiel, as informações da suposta relação (entre a imunização e o autismo) já haviam sido espalhadas por muitos países (Saraiva \& Faria, 2019), o que contribui para o acirrado aumento de seguidores ao movimento antivacina, enriquecido pela mídia social e propagação de diversas fake news.

\subsection{Testes da relação da vacinação com o autismo}

Pesquisas sérias já foram realizadas para análise da suposta relação: tríplice viral e autismo. Dentre os estudos, salienta-se uma pesquisa de caso controle realizado na Polônia com crianças de 2 a 15 anos com diagnóstico de autismo, onde foram utilizados 2 controles para cada caso (96 casos e 192 controles, com uma mediana de idade de 7,5 anos, sendo os participantes $91,2 \%$ meninos e 19,8\% meninas) - pareados pelo ano de nascimento, sexo e médico.

É possível identificar, no Gráfico 1, que a porcentagem de crianças não vacinadas foi maior nos casos do que nos controles. Diante dos dados do gráfico é perceptível que as crianças vacinadas antes do diagnóstico, o risco de autismo foi menor no grupo vacinado em relação ao não vacinado, como também nos vacinados apenas contra o sarampo. De acordo com o estudo, é perceptível que não há associação da vacina e do autismo e, ainda, demonstra que a não imunização da tríplice viral é um risco à população, uma vez que pode estimular recrescimento destas doenças (Almeida \& Olmos, 2010). 
Gráfico 1: Estudo publicado avaliando crianças de 2 a 15 anos com autismo relacionando as crianças vacinadas contra sarampo entre 12 e 18 meses, não vacinadas, as vacinadas com a vacina tríplice viral e a porcentagem de desencadeamento para o autismo.

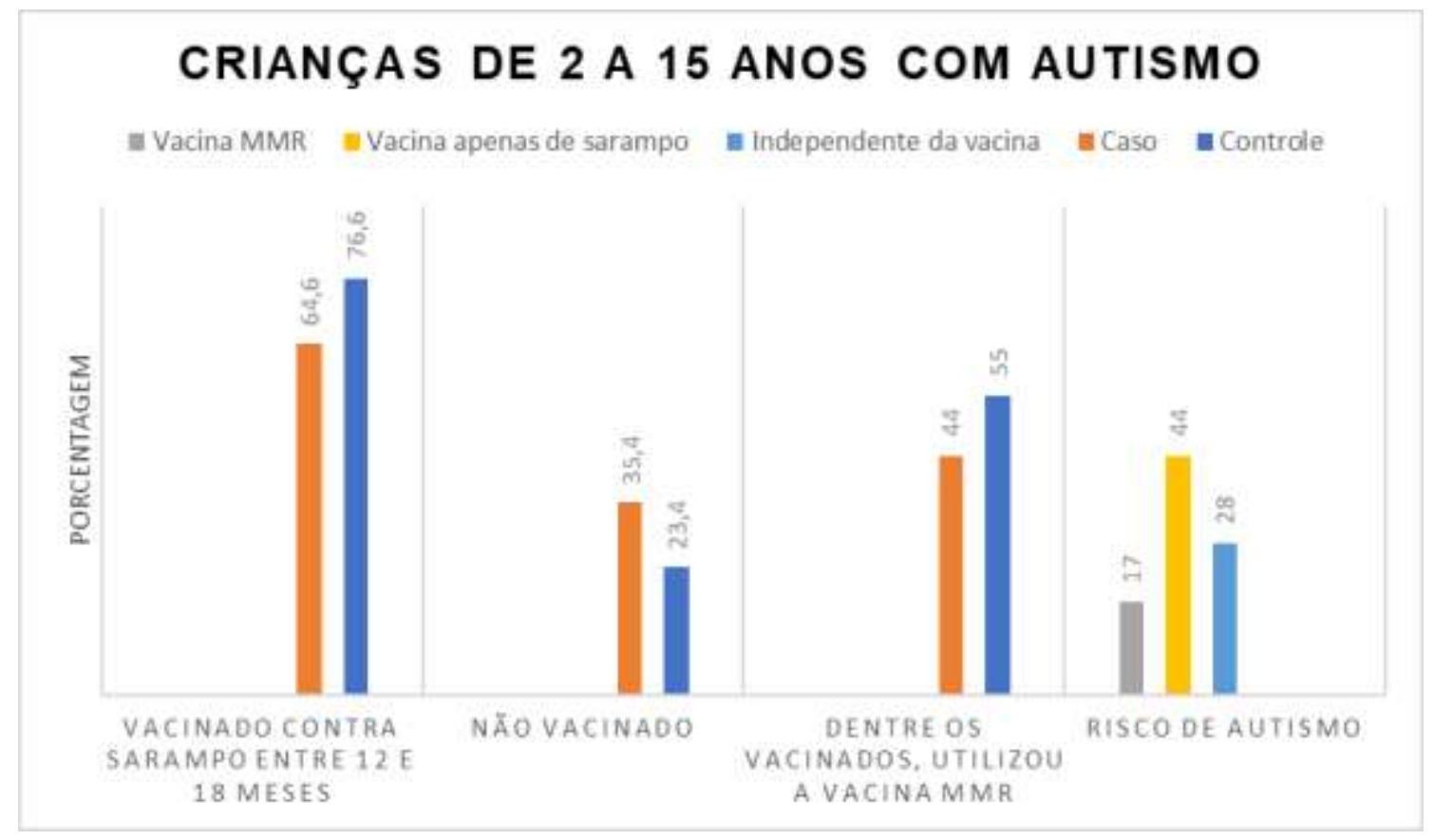

Legenda: MMR - Measles, Mumps and Rubella

Fonte: Autores.

Outro estudo populacional realizado em cinco distritos de saúde na região nordeste de Londres, sugere que a proporção de crianças com regressão do desenvolvimento, que correspondem a 25\%, ou com sintomas intestinais (causa também relacionado à imunização) contabilizando $17 \%$, não se alterou significativamente em relação à introdução ou não da vacinação MMR (Measles, Mumps and Rubella) ou tríplice viral durante 20 anos de observação (Taylor, et al., 2002).

Já, uma pesquisa feita em Montreal, Canadá, em nascimentos de 1987 a 1998, na qual a taxa de autismo aumentou significativamente quando a taxa vacinal decai, além da taxa de autismo aumentar antes e depois da introdução da segunda dose da vacina em 1996 sem risco aumentado - como visível no Gráfico 2 - ainda, houve análises adicionais, mas sem nenhuma compatibilidade foi vista (Fombonne, et al., 2006). 
Gráfico 2: Estudo que relaciona a cobertura vacinal da tríplice viral com a taxa de autismo, além da reintrodução da segunda dose da vacina em 1996, em crianças nascidas de 1987 a 1998.

\section{COBERTURA VACINAL DA TRÍPLICE VIRAL}

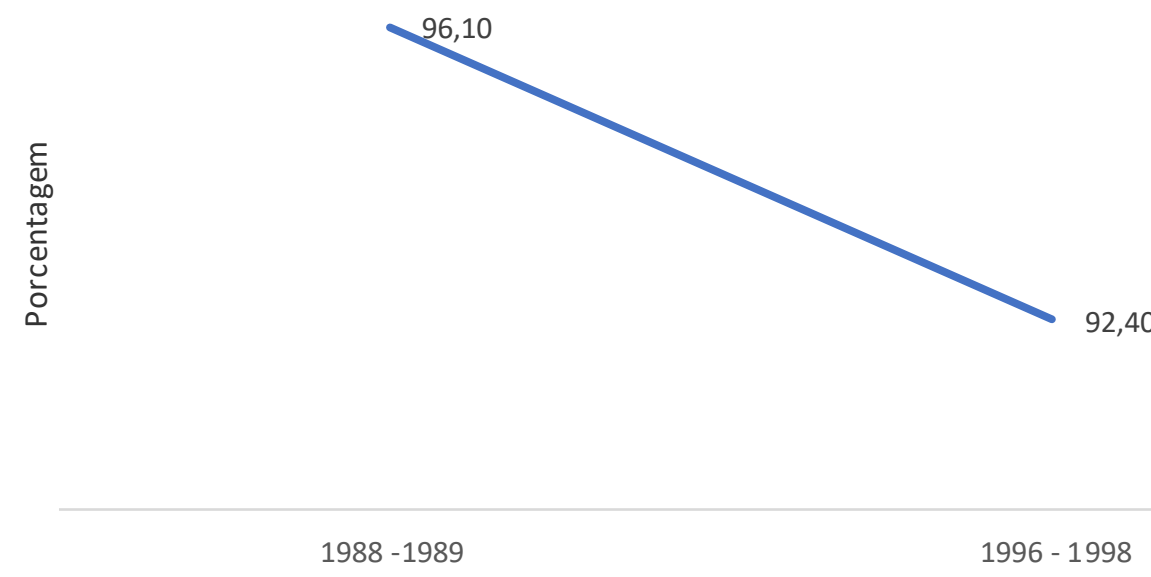

1987 - 1998: média de 93\%

Fonte: Autores.

A Finlândia, em 1982, aderiu simultaneamente à vacina MMR (Measles, Mumps and Rubella) a um sistema de vigilância nacional para detectar seus efeitos colaterais. Desse modo, 1,8 milhões de pessoas foram imunizadas (quase 3 milhões de doses até o fim de 1996) com 173 reações, da MMR, graves - 77 reações neurológicas, 73 alérgicas, 22 reações diversas e 1 morte, com a convulsão febril a reação mais comum - sendo que $45 \%$ foram comprovados, provavelmente, decorrentes da vacina ou agravado por algum outro fator. Sendo assim, uma proporção causal possível ou indeterminada de 5,3 para 100.000 vacinados ou 3,2 para 100.000 doses da vacina, ou seja, efeitos colaterais raros (Patja, et al., 2000).

Segundo o Gráfico 3, a pesquisa efetuada da década de 1980 até o final da década de 1990, demonstra na linha azul a Califórnia, Suécia e Dinamarca com exposição vacinal do componente timerosal (presente na tríplice viral), os resultados dos três países comprovam o início do aumento do autismo entre 1985 e 1989 e aceleração numérica principalmente a partir de 1990. Enquanto a linha laranja, mostra que nos Estados Unidos a dose média de timerosal das vacinas aumentou ao longo da década de 1990, já a linha cinza determina o timerosal nas vacinas na Suécia e na Dinamarca - com reduzidas taxas já nas décadas de 1970 e 1980 - diminuíram ainda mais no fim da década de 1980 até sua eliminação no início da década de 1990. Consequentemente, a hipótese de que timerosal é responsável pelo crescimento dos casos de autismo é equivocada (StehrGreen, 2003). 
Gráfico 3: Estudo sobre a hipótese da relação entre a vacina tríplice viral e o componente vacinal timerosal entre a década de 1980 e final de 1990.

\section{HIPÓTESE DE TIMEROSAL}

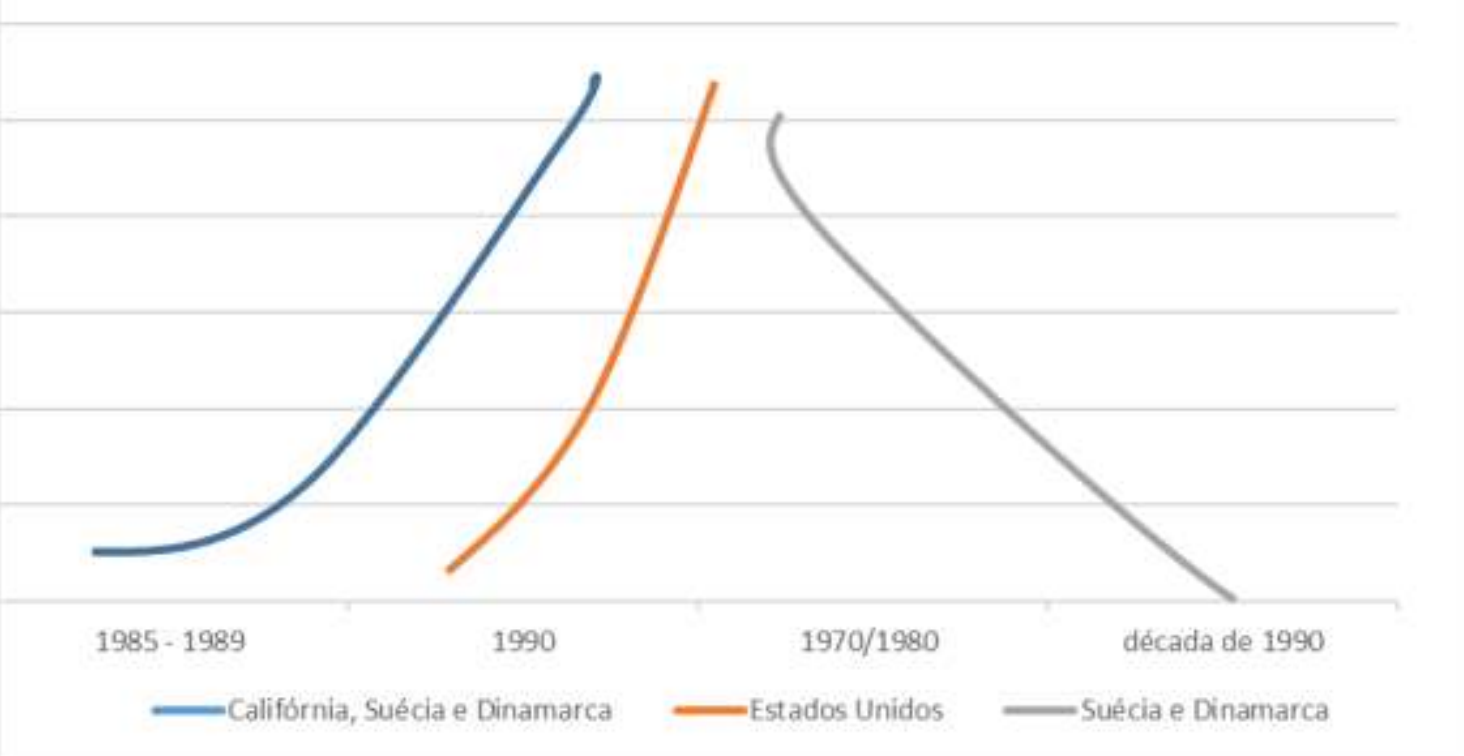

Fonte: Autores.

Uma análise executada em jardins de infância na Califórnia/EUA com nascimentos entre 1980 a 1994 e registo de imunização verificadas, resultou na garantia de nenhuma correlação entre o autismo e a vacina MMR, já que, de acordo com o Gráfico 4, para os nascimentos de 1980-1994 houve um aumento do número de casos de autismo (crescimento de 373\%), porém a cobertura vacinal no mesmo período foram muito menores e de menor duração, sendo que aos 24 meses foi de $72 \%$ para $82 \%$ (Dales, et al., 2001). 
Gráfico 4: Estudo publicado sobre a relação do autimos e da vacina tríplice viral entre 1980 e 1994.

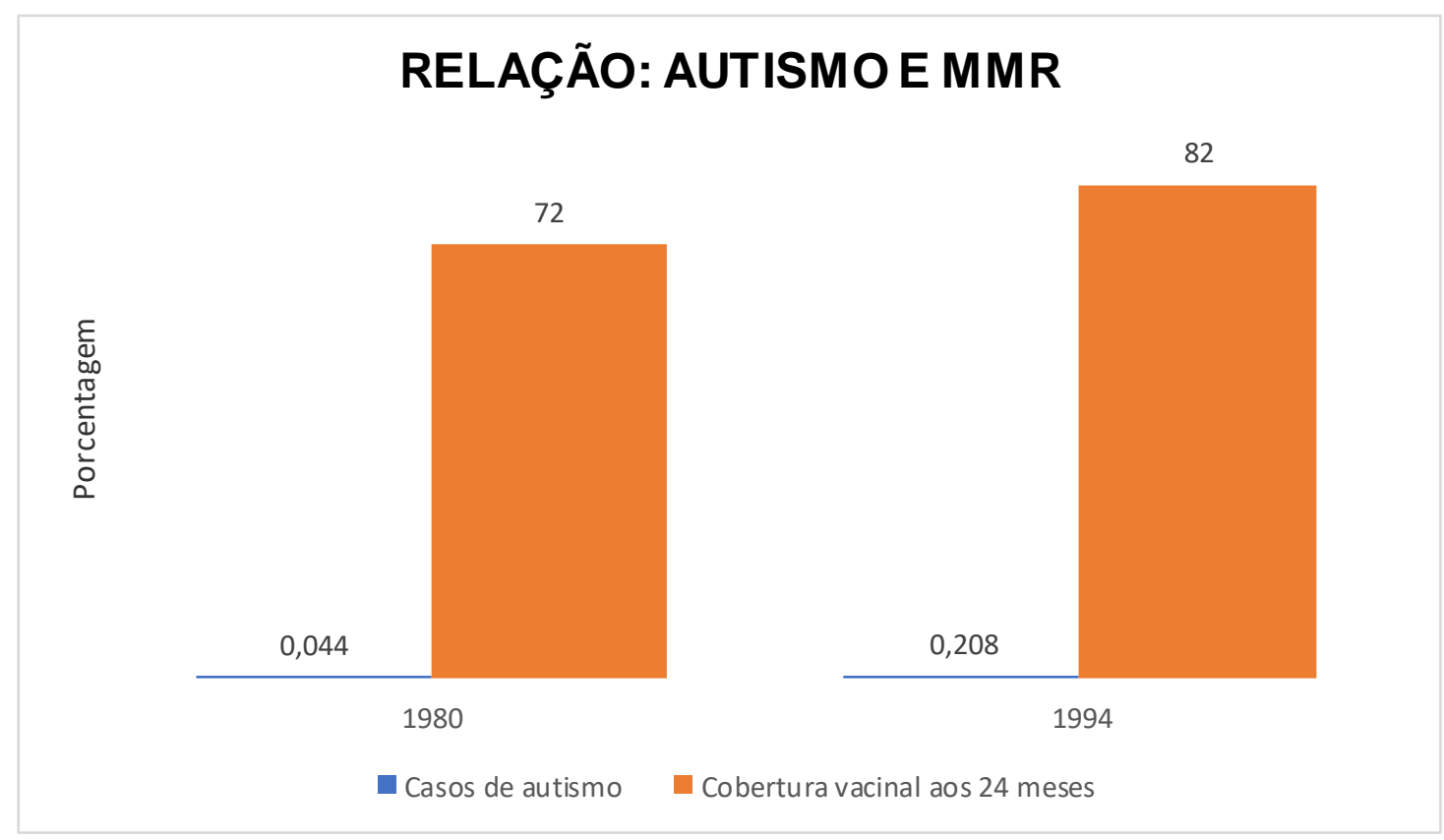

Legenda: MMR - Measles, Mumps and Rubella Fonte: Autores.

Diante dos estudos apresentados e comprovados em diversos países é indiscutível a falsa correlação criada pelo cientista Wakefield, ou seja, não há qualquer relação do autismo com a vacina tríplice viral (MMR), sendo esta ainda a forma mais eficaz de erradicar a doença respiratória em comento, prevenindo assim a sua disseminação, taxa de transmissão e redução da taxa de mortalidade.

\subsection{Reincidência do sarampo}

Atualmente, surtos de sarampo tem acometido o mundo, incluído países desenvolvidos, como França e Estados Unidos, ou em desenvolvimento sobretudo na Ásia e na África. Ainda, é fundamental declarar que um Comitê Internacional de Especialistas declarou a região das américas livre de sarampo em 2016, embora evidenciando a atividade do vírus em aspecto mundial (Ribeiro, et al., 2015).

Entretanto, infelizmente, em 2017 a doença volta para a América, gerando casos em países como: Argentina, Canadá, Estados Unidos, Venezuela, Antígua e Barbuda, Brasil, Colômbia, Guatemala, Peru e México. Já em 2018 , além de 12 países notificarem em casos, 2 desses (Brasil e Venezuela) relatam também mortes (Brasil, 2019). Os dados da atualização epidemiológica da Organização Pan-Americana da Saúde (OPAS), com dados fechados no dia 7 de agosto de 2019, mostram que a doença foi identificada em 14 países, de 1 janeiro a 27 de julho, sendo as maiores proporções registrada (OPAS, 2019a; OPAS, 2019c) as demonstradas no Gráfico 5: 
Gráfico 5: Casos de sarampo registrados, de maiores proporções, no período de 1 de janeiro a 27 de julho de 2019 na América.

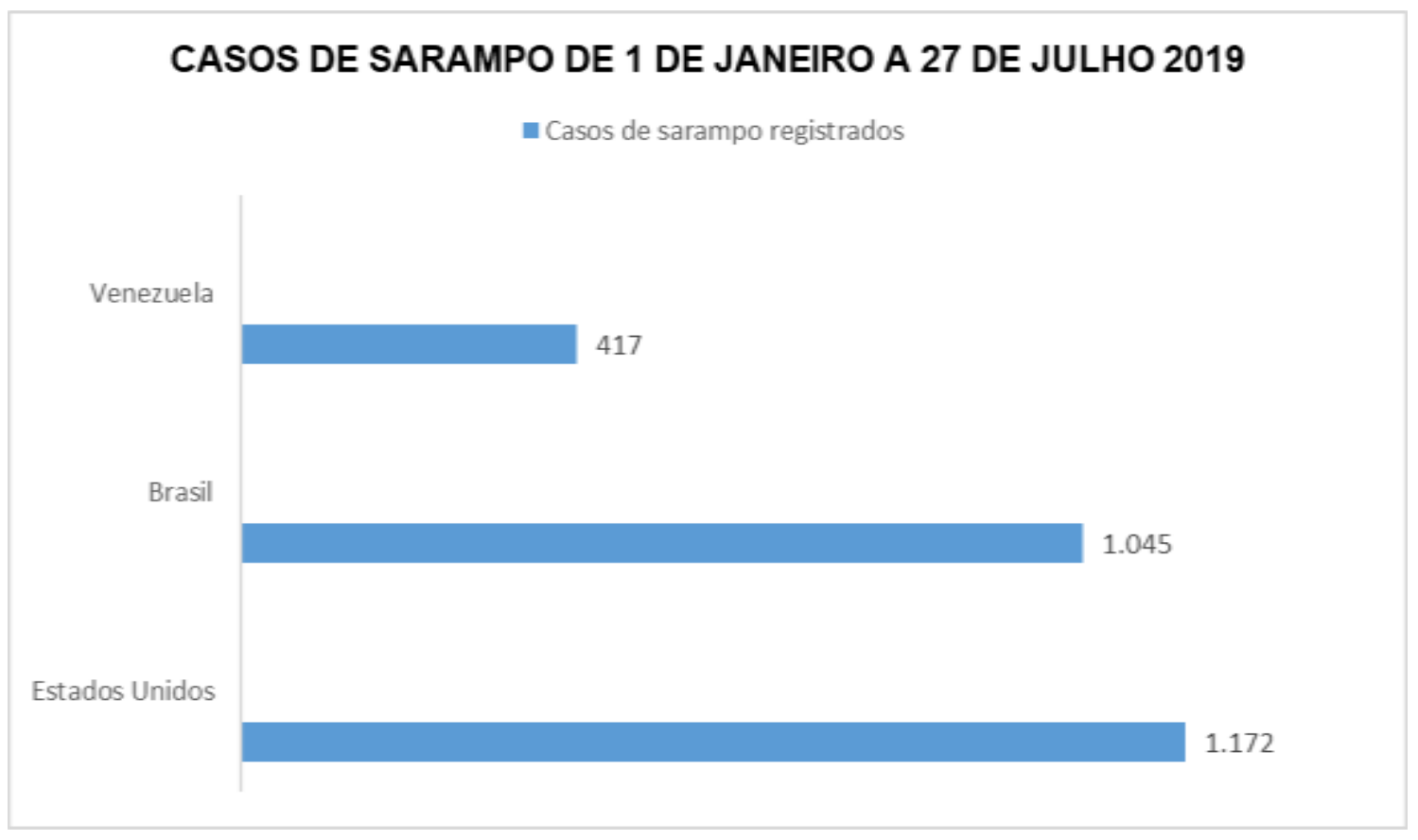

Fonte: Autores.

Posteriormente, em 2019, dados mostram que os casos notificados de sarampo cresceram $300 \%$ no mundo todo em relação aos primeiros meses de 2018. Os países que registraram surtos da doença foram: República Democrática do Congo, Etiópia, Geórgia, Cazaquistão, Quirguistão, Madagascar, Mianmar, Filipinas, Sudão, Tailândia e Ucrânia, com várias mortes, principalmente entre crianças (OPAS, 2019b).

Nessa questão, o Brasil erradicou o sarampo desde 2000, visto que era uma doença endêmica no território brasileiro. Entretanto, apesar de eliminado os casos importados permaneceram. Desse modo, durante 13 anos (2001-2014) o número médio anual de casos notificados da doença foi de 50 (Leite, et al., 2015). Mundialmente, o número de casos de sarampo nesse período foi reduzido, já que os casos diminuíram cerca de 548.300 em 2000 para uma estimativa de 114.900 em 2014 (Connor, et al., 2017). Já uma análise de 2015 a 2018 revela que internações decorrentes do sarampo varia de 05 para 835 nos estados fronteiriços, sendo que 94,32\% dessas são remetentes a Roraima e Amazonas, enquanto o Pará adquiriu menor cobertura vacinal durante esses 4 anos $(57,63 \%)$.

Indiscutivelmente, o processo migratório contribui para o aumento percentual dos casos da doença, mas não se pode esquecer que a cobertura vacinal, na maioria dos estados, não atingiu a meta de 95\% de abrangência (Vasconcelos, et al., 2020).

Vale ressaltar: em 2018, 355 casos de sarampo foram relatados em Roraima, todos com linhagem do genótipo provenientes do surto de 2017 na Venezuela, sendo que crianças menores de um ano foram as mais afetadas (812,1/100.000), seguidas por crianças de 1 a 4 anos (245,7/100.000); no estado do Amazonas houve 9.778 casos da doença (Doocy, et al., 2019). No Brasil, o Ministério da Saúde, preconiza a estratégia de vacinação (Brasil, 2020) demonstrada nas Tabelas 1 e 2 : 
Tabela 1: Estratégia de vacinação da tríplice viral determinada pelo Ministério da Saúde, relacionando as doses com o público alvo e idade.

\begin{tabular}{|l|l|l|}
\hline DOSE & PÚBLICO ALVO & IDADE \\
\hline Dose zero & Todas as crianças & $\begin{array}{l}6 \text { meses a menores de 1 ano de } \\
\text { idade (dose extra) }\end{array}$ \\
\hline Primeira dose & Crianças & 12 meses completos (1 ano). \\
\hline Segunda dose & Crianças & 15 meses de idade (última dose) \\
\hline
\end{tabular}

Fonte: Autores.

Tabela 2: Estratégia de vacinação da tríplice viral determinada pelo Ministério da Saúde, relacionando a idade com o número de doses necessárias.

\begin{tabular}{|l|l|}
\hline IDADE & NÚMERO DE DOSES \\
\hline Entre 1 e 29 anos & $\begin{array}{l}\text { Primeira dose comprovada, completar o esquema vacinal com a segunda } \\
\text { dose da vacina }\end{array}$ \\
\hline 1 a 29 anos & $\begin{array}{l}\text { Duas doses da vacina quando não tomaram nenhuma dose, perderam o } \\
\text { cartão vacinal ou não se lembram }\end{array}$ \\
\hline 30 a 59 anos & $\begin{array}{l}\text { Apenas uma dose quando não tomaram nenhuma dose da vacina, perderam } \\
\text { o cartão vacinal ou não se lembram }\end{array}$ \\
\hline $\begin{array}{l}\text { A vacina é contraindicada durante a gestação, pois pode diminuir a imunidade da mulher, por se tratar de uma } \\
\text { vacina produzida a partir de um vírus vivo atenuado }\end{array}$
\end{tabular}

Fonte: Autores.

Além disso, o plano "Dose zero" foi adotada pelo Ministério da Saúde em agosto de 2019 para tenta minimizar o crescimento do sarampo no país, visto que até o início do mês de fevereiro já havia registro de três óbitos de crianças com idade inferior ou igual a 18 meses (um no estado do Rio de Janeiro, outro no estado do Pará e o terceiro em São Paulo) por essa doença viral (Brasil, 2019c). É fundamental verificar que no ano de 2019, no Brasil, houve a confirmação de 13.181 casos nos estados de São Paulo, Paraná, Rio de Janeiro, Minas Gerais, Pernambuco e Bahia. Dessa forma, o Gráfico 6, demonstra os casos de sarampo presentes no país (Brasil, 2019b). 
Gráfico 6: Casos de sarampo, no ano de 2019, notificados, confirmados, descartados e ainda sob investigação.

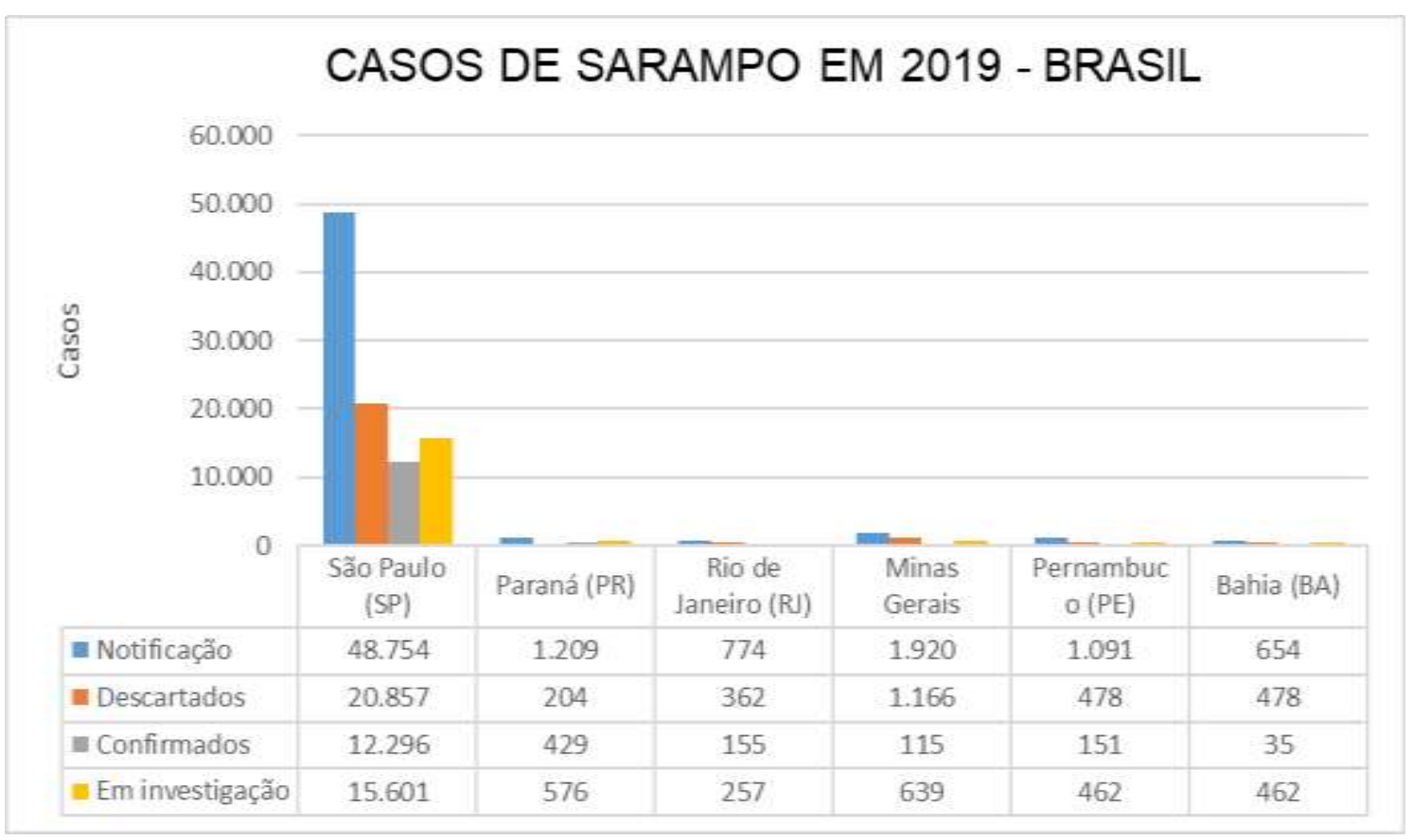

Fonte: Autores.

Em 2020, as notificações dos casos de sarampo foram menores devido a luta para combater a pandemia do Coronavírus da COVID-19, o qual resultou em interrupções nas campanhas de vacinações para minimizar os surtos de sarampo no Brasil. Muitos países estão enfrentando surtos da doença, apenas Brasil, República Congo-Africana, República Democrática do Congo, Etiópia, Nepal, Nigéria, Filipinas e Somália, retomaram suas campanhas de vacinação após as paralisações (OPAS, 2020).

Em janeiro de 2021, foi descrito casos de sarampo entre as semanas de 29/12/2019 a 19/12/2020, conforme Tabela 3.

Tabela 3: Casos de sarampo relatados entre 29/12/2019 a 19/12/2020, identificando os casos notificados, confirmados, descartados e ainda sob investigação.

\begin{tabular}{|c|c|c|c|}
\hline \multicolumn{3}{|c|}{ Casos de sarampo } \\
\hline Notificação & Confirmado & Descartados & Sob investigação \\
\hline 16.703 & 8.419 & 7.913 & 371 \\
\hline
\end{tabular}

Fonte: Autores.

De acordo com dados da Secretaria de Vigilância em Saúde, quatro estados mantêm surto ativo: Pará com 5.375 casos confirmado, Rio de Janeiro com 1.347 casos, São Paulo com 864 casos e Amapá com 177 casos. As maiores ocorrências de óbitos pela doença foram nos estados do Pará com 5 óbitos, Rio de Janeiro e São Paulo com 1 caso cada (Associação Paulista de Medicina, 2021).

Diante do apresentado, o sarampo - doença de transmissão respiratória, novamente, começou a ser identificado. Isso decorre da hesitação e recusa vacinal, muitas vezes influenciadas por falsas notíciais e pelo movimento antivacina que tem ganhado força, principalmente com a ajuda da internet e da mídia social ao divulgarem informações incorretas ou distorcidas por não buscarem a veracidade dos fatos. É inaceitável e lamentável que uma doença com vacinação gratuita esteja aumentando gradativamente no país (Machado, et al., 2020). 


\section{Considerações Finais}

A análise do estudo revisado aponta que o sarampo é uma doença respiratória comum e altamente contagiosa. No entanto, é denominada perigosa quando não tratada eficientemente. Atualmente, a forma mais eficaz de combate à doença se dá através da vacinação, todavia, embora de grande importância, a vacina tríplice viral, não impede o seu contágio, porém impede sua agravação e consequentemente o óbito. A vacinação é uma segurança coletiva, não apenas individual, contribuindo para reduzir a transmissibilidade, por meio de uma menor carga viral. Ademais, é fornecida gratuitamente a toda população.

Essa revisão narrativa, apesar de limitada a estudos já existentes no meio digital, serve como importante alerta para a reintrodução do sarampo no Brasil e no mundo, além de seu agravamento por se tratar de uma doença antes erradicada. Entretanto, os números com o passar dos anos tem crescido gradativamente juntamente com o apoio dos ideais antivacinação. Isso porque apesar dos estudos comprovando a fraudulenta contextualização entre a vacinação e o autismo, as mídias digitais e os próprios cidadãos não se certificam da veracidade das informações antes de compartilhá-las e seguí-las.

Sugere-se que o presente trabalho possa contribuir para pesquisas futuras, envolvendo o impacto atual do movimento antivacina, considerando a conscientização quanto a segurança, eficiência e necessidade da imunização. Somente assim, a saúde pública garantirá uma vida social preventiva e curativa aos cidadãos.

\section{Referências}

Almeida, F. J., \& Olmos, R. D. (2010, 23/05). Vacina contra Sarampo Caxumba e Rubéola e Autismo. Falta de associação entre vacina contra sarampo, caxumba e rubéola e autismo em crianças: um estudo caso controle. http://www.medicinanet.com.br/conteudos/ar tigos/3241/vacina_contra_sarampo_caxumba_e_rubeola_e_autismo.htm.

Associação Paulista de Medicina. (2021). Brasil notifica mais de 16 mil casos de sarampo até 19 de dezembro. http://associacaopaulistamedicina.org.br/noticia/brasil-notifica-mais-de-16-mil-casos-de-sarampo-ate-19-de-dezembro.

O'Connor, P., Jankovic, D., Muscat, M., Ben-Mamou, M., Reef, S., Papania, M., Singh, S., Kaloumenos, T., Butler, R., \& Datta, S. (2017). Measles and rubella elimination in the WHO Region for Europe: progress and challenges. Clinical Microbiology and Infection 23 (2017) 504-510. https://doi.org/10.1016/j.cmi.2017.01.003.

Dales, L., Hammer, S. J., \& Smith, N. J. (2001). Time trends in autism and in MMR immunization coverage in California. JAMA. 2001; 285(9):1183-1185. doi:10.1001/jama.285.9.1183.

Destefano, F., \& Shimabukuro, T. T. (2019). The MMR Vaccine and Autism. Annual Review of Virology 2019 6:1, 585-600. https://doi.org/10.1146/annurevvirology-092818-015515.

Doocy, S., Page, K. R., Hoz, F. D. L., Spiegel, P., \& Beyrer, C. (2019). Venezuelan Migration and the Border Health Crisis in Colombia and Brazil. Journal on Migration and Human Security 7(3). https://doi.org/10.1177/2331502419860138.

Fombonne, E., Zacarian, R., Benett, A., Meng, L., \& McLean-Heywood, D. (2006). Pervasive developmental disorders in Montreal, Quebec, Canada: prevalence and links with immunizations. Pediatrics. $2006 \mathrm{Jul} ; 118(1):$ e139-50. https://doi.org/10.1542/peds.2005-2993

Gerber, J. S. \& Offit, P. A. (2009). Vaccines and Autism: A Tale of Shifting Hypotheses. Clin Infect Dis. 2009 February 15; $48(4)$ : 456-461. https://doi.org/10.1086/596476.

Leite, R. D., Barreto, J., \& Monteiro, D. (2015). Measles Reemergence in Ceará, Northeast Brazil, 15 Years after Elimination. Emerging Infectious Diseases, 21(9), 1681-1683. https://dx.doi.org/10.3201/eid2109.150391.

Machado, L. F. B., Ferreira, N. M. D. S., Damasceno, C. R., Santos, A. C. P. D., Pereira, C. D., \& César, J. J. (2020). Recusa vacinar e o impacto no ressurgimento de doenças erradicadas. Brazilian Journal of Surgery and Clinical Research - BJSCR 32(1), 12-16. https://www.mastereditora.com.br/periodico/20200907_164040.pdf.

Ministério da Sáude. (2019a). Guia de Vigilância em Saúde. (3a ed.), volume único. https://portalarquivos2.saude.gov.br/images/pdf/2019/agosto/21/Guia-deVigilancia-em-Saude-Sarampo.pdf.

Ministério da Saúde. (2019b). Secretaria de Vigilância em Saúde. Vigilância Epidemiológica do Sarampo no Brasil 2019 : Semanas Epidemiológicas 36 a 47 de 2019, 50(37). https://portalarquivos2.saude.gov.br/images/pdf/2019/dezembro/16/Boletim-epidemiologico-SVS-37-interativo-final.pdf.

Ministério da Saúde. (2019c). Secretaria de Vigilância em Saúde. Vigilância epidemiológica do sarampo no Brasil 2020 : Semana Epidemiológica 01 (29/12/2019) a 06 (08/02/2020). 51(09). http://portalarquivos.saude.gov.br/images/pdf/2020/marco/04/Boletim-epidemiologico-SVS-09-final.pdf.

Secretaria do estado de saúde. (2020). Sarampo. https://www.saude.mg.gov.br/sarampo.

Monteiro, S. A. M. G., Takano, O. A., \& Waldman, E. A. (2011). Avaliação do sistema brasileiro de vigilância de eventos adversos pós-vacinação. Revista Brasileira de Epidemiologia, 14(3), 361-371. https://doi.org/10.1590/S1415-790X2011000300002. 
Organização Panamericana de Saúde - OPAS. (2019a). Brasil e Paraguai lançam campanha para intensificar vacinação em áreas de fronteira. 2019. https://www.paho.org/bra/index.php?option=com_content\&view=article\&id=6021:brasil-e-paraguai-lancam-campanha-para-intensificar-vacinacao-em-areasde-fronteira\&Itemid=812.

Organização Panamericana de Saúde - OPAS. (2019b). Casos de sarampo cresceram $300 \%$ no mundo conforme dado preliminares de 2019. https://www.paho.org/bra/index.php?option=com_content \&view=article \&id=5913:casos-de-sarampo-cresceram-300-no-mundo-conforme-dados-preliminaresde-2019\&Itemid=820.

Organização Panamericana de Saúde - OPAS. (2019c). Doze países das Américas notificam mais de 17 mil casos confirmados de sarampo. https://www.paho.org/bra/index.php?option=com_content\&view=article\&id=5853:doze-paises-das-americas-notificam-mais-de-17-mil-casos-confirmados-desarampo\&Itemid=820.

Organização Panamericana de Saúde - OPAS. (2020). Mortes por sarampo em todo o mundo sobem $50 \%$ entre 2016 e 2019 , com mais de 207,5 mil vidas perdidas em 2019. https://www.paho.org/pt/noticias/12-11-2020-mortes-por-sarampo-em-todo-mundo-sobem-50-entre-2016-e-2019-com-mais-2075-mil.

Patja, A., Davidkin, I., Kurki, T., Kallio, M. J., Valle, M., \& Peltola, H. (2000). Serious adverse events after measles-mumps-rubella vaccination during a fourteen-year prospective follow-up. The Pediatric infectious disease journal, 19(12), 1127-1134. https://doi.org/10.1097/00006454-200012000-00002.

Petraglia, T. C. D. M. B., Farias, P. M. C. D. M., Sá, G. R. S. E., Santos, E. M. D., Conceição, D. A. D., \& Maia, M. D. L. D. S. (2020). Falhas vacinais: avaliando vacinas febre amarela, sarampo, varicela e caxumba. Cadernos de Saúde Pública, 36(Supl. 2), e00008520. https://doi.org/10.1590/0102$311 \times 00008520$

Rao, T. S., \& Andrade, C. (2011). The MMR vaccine and autism: Sensation, refutation, retraction, and fraud. Indian journal of psychiatry, 53(2), 95-96. https://doi.org/10.4103/0019-5545.82529.

Ribeiro, C., Menezes, C., \& Lamas, C. (2015). Sarampo: achados epidemiológicos recentes e implicações para a prática clínica. Artigo Especial - 1(2) (2015). http://publicacoes.unigranrio.edu.br/index.php/amp/article/view/3343/1568.

Rothbarth, R. (2018). Vacinação: direito ou dever? A emergência de um paradoxo sanitário e suas consequências para a saúde pública. https://www.teses.usp.br/teses/disponiveis/6/6143/tde-11102018-123140/publico/RenataRothbarthSilva_MTR_REVISADA.pdf.

Rother, E. T. (2007). Revisão sistemática X revisão narrativa. Acta Paulista de Enfermagem,20(2), v-vi. https://dx.doi.org/10.1590/S010321002007000200001

Saraiva, L. J. C., \& Faria, J. F. D. (2019). A Ciência e a Mídia: A propagação de Fake News e sua relação com o movimento anti-vacina no Brasil. Intercom Sociedade Brasileira de Estudos Interdisciplinares da Comunicação. https://portalintercom.org.br/anais/nacional2019/resumos/R14-1653-1.pdf.

Schäfer, M. G., Bulegon, J. S., Negrete, B. B., \& Parisi, M. M. (2019) Movimento Antivacina: sua origem e os impactos negativos na sociedade atual. Vigilância em Saúde: Ações de Promoção, Prevenção, Diagnóstico e Tratamento, v.6. https://www.publicacoeseventos.unijui.e du.br/index.php/conintsau/article/view/11400/9999.

Scliar, M. (2007). História do Conceito de Saúde. Physis: Revista de Saúde Coletiva, 17(1), 29-41. https://dx.doi.org/10.1590/S0103-73312007000100003.

Stehr-Green, P., Tull, P., Stellfeld, M., Mortenson, P. B., \& Simpson, D. (2003). Autism and thimerosal-containing vaccines: lack of consistent evidence for an association. American journal of preventive medicine, 25(2), 101-106. https://doi.org/10.1016/s0749-3797(03)00113-2.

Taylor, B., Miller, E., Lingam, R., Andrews, N., Simmons, A., \& Stowe, J. (2002). Measles, mumps, and rubella vaccination and bowel problems or developmental regression in children with autism: population study. BMJ (Clinical research ed.), 324(7334), 393-396. https://doi.org/10.1136/bmj.324.7334.393.

Vasconcelos, L. A. de, Santos, J. N. G., Arenhardt, A. S., Moreira, A. M. de A., Vaz, H. J., Silva, J. L., Ramos, V. de J., Lima, I. O. F., Teixeira, F. de J. M., \& Pereira, J. L. dos S. (2020). Análise epidemiológica do sarampo entre os estados brasileiros que fazem fronteira com outros países, Brasil, 2015 a 2018. Research, Society and Development, 9(6), e176963583. https://doi.org/10.33448/rsd-v9i6.3583.

Vasconcellos-Silva, P. R., Castiel, L. D., \& Griep, R. H. (2015). A sociedade de risco midiatizada, o movimento antivacinação e o risco do autismo. Ciência \& Saúde Coletiva, 20(2), 607-616. https://dx.doi.org/10.1590/1413-81232015202.10172014.

Xavier, A. R., Rodrigues, T. S., Santos, L. S., Lacerda, G. S., \& Kanaan, S. (2019). Diagnóstico clínico, laboratorial e prof ilático do sarampo no Brasil. Jornal Brasileiro de Patologia e Medicina Laboratorial, 55(4), 390-401. Epub September 02, 2019. https://dx.doi.org/10.5935/1676-2444.20190035. 